\title{
Os gêneros literários e a indústria cultural no século xx: relações crítica entre teatro épico, arte e política
}

\author{
The literary genres and cultural industry in the \\ twentieth century: critical relations between epic \\ theatre, art and politics
}

Bruno Policani Filippo ${ }^{1}$ 


\section{Resumo}

O ensaio aborda a relação entre gêneros literários e industrial cultural. Partindo das formulações de Platão e Aristóteles e chegando até o século XX, mostra como essa imbriçação permitiu outras formas de pensar a transformação da realidade social e política por meio da arte. Com embasamento na Teoria Literária, estudam-se os gêneros Épico, Lírico e Dramático e o entrelaçamento entre eles, de que resultou, na dramaturgia, o teatro épico. $O$ recurso às teorias de Walter Benjamin ilumina o papel do teatro épico como uma das expressões mais significativas, a partir da segunda metade do século XX, de manifestar inconformismo social e político em plena era de massificação na qual a indústria cultural parecia condenar o gênero Épico ao esquecimento.

Palavras-Chave: Teoria literária, gêneros literários, teatro épico, indústria cultura.

\section{Abstract}

This essay focuses on the relationship between literary genres and cultural industry. Starting from the formulations of Plato and Aristotle and reaching the twentieth century, it shows how this overlap allowed other ways of thinking the transformation of social and political reality through art. With basis in Literary Theory, we study the genres Epic, Lyric and Dramatic and the links between them, which resulted in the drama, the epic theater. The use of theories of Walter Benjamin illuminates the role of epic theater as one of the most important works from the second half of the twentieth century, to express social and political discontent in the era of mass in which the cultural industry seemed to condemn the genre Epic oblivion.

Keywords: Literary theory, literary genres; epic theater; cultural industry.

ISSN: $1808-3129$

\footnotetext{
${ }^{1}$ Mestrando em Teatro pela Universidade do Estado de Santa Catarina (UDESC)

Florianópolis, SC, Brasil

brunofilippo2000@yahoo.com.br
} 


\section{INTRODUÇÃO}

A Teoria Literária debruça-se sobre a definição dos gêneros tendo por parâmetro seminal a República, de Platão, e a Poética, de Aristóteles. A divisão entre poesia lírica, poesia épica e poesia dramática encontrou nos pais da filosofia ocidental as primeiras - e, ainda hoje, importantes - tentativas de sistematização.

A emergência dos meios de comunicação de massa - cinema, rádio e televisão - entre o fim do século XIX e as primeiras décadas do século XX - encontrou no drama lírico, fusão da Lírica com a Dramática, a estrutura mais adequada para apelar à sensibilidade da audiência massiva. Paralelamente, porém, ao declínio da Épica, buscou-se entrelaçá-lo com a Dramática com o propósito bem diverso: ao invés de diversão: a conscientização dos problemas sociais, econômicos e políticos. 


\title{
TEXTO
}

A taxionomia dos gêneros literários encontrou no teatro político do início do século XX um entrelaçamento de formas de que derivou a expressão "teatro épico". Arte da representação, o teatro incorporou em seu conteúdo temas políticos não somente pela perspectiva mimética de retratar a sociedade - o que, na história do teatro, é tão antigo quanto ele próprio -, mas com o objetivo de conscientizar o público, levando-o à reflexão e à consciência transformadora de uma realidade. Como nota Margot Berthold em sua História Mundial do Teatro:

\begin{abstract}
A relação entre o teatro e a política tem sido tensa há dois mil e quinhentos anos. Aristófanes investiu, a partir do palco, contra os demagogos e advogados da Guerra do Peloponeso; ele o fez na soberana forma artística da Comédia Ártica, que atrai como forma teatral original mesmo lá onde as alusões políticas não são compreendidas. Mas quando se trata somente de provocação política, a sua atrelagem ao palco torna-se dispensável. (BERTHOLD, 2011, p.502)
\end{abstract}

Bertolt Brecht, dialeticamente, buscou superar essa tensão. E efetivamente o fez no momento histórico em que as inovações tecnológicas desenvolviam a indústria cultural. Isso lhe possibilitou a utilização cênica de recursos extrateatrais - como projeção de imagens, sons, cartazes, panfletos - com a consciência de que o valor estético de uma obra era o que caracterizava a obra.

Referir-se a "teatro épico" tornou-se quase o mesmo que se referir a "teatro político"- e, por ironia, evoca quase pavlovianamente o nome de Bertolt Brecht. Assim, a sinonímia política-épica como que dissolve a diferença entre forma e conteúdo: toma as características de um gênero pelos efeitos que os assuntos tratados pretendem provocar. Por isso, é necessário pensar por que a forma épica foi a que melhor se encaixou na ruptura da forma dramática tradicional e permitiu sua transformação em vanguarda artística e propagandista. Como nota o teórico do teatro Anatol Rosenfeld:

A maneira pela qual é comunicado o mundo imaginário pressupõe certa atitude em face deste mundo ou, contrariamente, a atitude exprime-se em certa maneira de comunicar. Nos gêneros manifestam-se, sem dúvida, tipos diversos de imaginação e de atitudes em face do mundo. (ROSENFELD, 2011, p.17)

Aristóteles, analisando as duas formas dramáticas de sua época - a comédia e a tragédia -, distinguiu-as pelos indivíduos que elas retratavam: na comédia, os de caráter inferior; na tragédia, os de caráter elevado. A tragédia, portanto, está próxima da épica na imitação das ações dos heróis, dos grandes homens de elevado valor na sociedade; mas, cotejando-as, Aristóteles estabeleceu a superioridade da tragédia:

Mas a tragédia é superior porque contém todos os elementos da epopeia (chega até a servir-se do metro épico), e demais, o que não é pouco, música e espetáculo cênico, que acrescem a intensidade dos prazeres que lhe são próprios. Possui, ainda, grande evidência representativa, quer na leitura, que na cena; e também a vantagem que resulta de, adentro de mais breves limites, perfeitamente realizar a imitação; além disso a imitação dos épicos é menos unitária (demonstra-o a possibilidade de extrair tragédias de qualquer epopeia) e, portanto, se pretendessem eles compor uma epopeia sobre uma única fábula trágica, se quisessem ser con- 
cisos, mesquinho resultaria o poema, se quisessem conformar-se às dimensões épicas, resultaria prolixo. (ARISTÓTELES, 2004, 1462b)

Pela monumentalidade dos fatos narrados (não à toa o substantivo épico adjetivou-se: qualifica hodiernamente algo de extraordinário), pelo distanciamento do tempo passado e pela presença objetiva do narrador, o gênero épico cria distância entre sujeito e objeto, entre significante e significado, com pouca identificação subjetiva do leitor com a história narrada.

Já a tragédia, como forma mais elevada do drama na definição do Estagirita, por despertar terror e piedade no público, purificando-o por meio da catarse, deveria respeitar a ordem dos fatos e a verossimilhança, pois isso é o que permite a identificação dos indivíduos; identificando-se o público com os heróis trágicos, seus conflitos individuais, seu destino traçado por forças que lhes são superiores, operase efeito inverso à da épica: aproximação do sujeito com o objeto, do significante com o significado. Embora determinado pelo contexto, o indivíduo e seus pathos, na escritura dramática, estão em primeiro plano - aí incluindo a comédia, com a qual, igualmente, o público se identificava pela verossimilhança.

Massaud Moisés, ao definir a poesia épica, ressalta como, nesta, os sentimentos individuais estão subordinados formalmente ao contexto da grande narrativa:

\footnotetext{
[...] A poesia deve girar em torno de assunto ilustre, sublime, solene, especialmente vinculado a cometimentos bélicos; deve prender-se a acontecimentos históricos, ocorridos há muito tempo, para que o lendário se forme ou/e permita que o poeta lhes acrescente com liberdade o produto da sua fantasia; o protagonista da ação há de ser um herói de superior força física e mental, embora de constituição simples, instintivo, natural; o amor pode inserir-se na trama heroica, mas em forma de episódios isolados; e, sendo terno e magnânimo, complementar harmonicamente as façanhas da guerra. (MOISÉS, 2004, p. 153) ${ }^{1}$
}

Os preceitos de Aristóteles tornaram-se canônicos na dramaturgia ocidental. Por isso, ao buscar alteração da relação sujeito-objeto no teatro, o teatro político pretendeu rompê-los. A opção pelos elementos da épica para provocar o efeito do distanciamento e, a partir desse momento, estimular o pensamento assentava-se, portanto, no pressuposto de que a mímese tradicional, aristotélica, estando em nível próximo da realidade, fazia o público identificar-se com ela, de modo que perdesse a distância crítica da realidade. Assim, o elemento narrativo justapõe-se à cena para trazer ao proscênio o contexto social e político que determina a ação das personagens.

No prefácio de Ascensão e Queda da Cidade de Mahagonny, Brecht estabeleceu um conhecido cotejo em que contrapõe tópicos do teatro dramático aos do teatro épico. Vejamo-la: 
Os gêneros literários e a indústria cultural no século xx: relações crítica entre teatro épico, arte e política

\begin{tabular}{|l|l|}
\hline Forma dramática de teatro & Forma épica de teatro \\
\hline O palco corporifica uma ação & O palco relata a ação \\
\hline $\begin{array}{l}\text { Compromete o espectador na ação } \\
\text { e consome sua atividade }\end{array}$ & $\begin{array}{l}\text { Transforma o espectador em observador } \\
\text { e desperta sua atividade }\end{array}$ \\
\hline Possibilita sentimentos & Obriga o espectador a tomar decisões \\
\hline Proporciona emoções, vivências & Proporciona conhecimentos \\
\hline O espectador é transportado para dentro da ação & O espectador é contraposta a ela \\
\hline Trabalha-se com a sugestão & Trabalha-se com argumentos \\
\hline Conservam-se as sensações & As sensações levam a uma tomada de consciência \\
\hline O homem se apresenta como algo conhecido previamente & O homem é objeto de investigação \\
\hline O homem é imutável & O homem se transforma e transforma \\
\hline A tensão em relação ao desenlace da peça & A tensão em relação ao andamento \\
\hline Uma cena existe em função da seguinte & Cada cena existe por si mesma \\
\hline Os acontecimentos decorrem linearmente & Decorrem em curvas \\
\hline Natureza não dá saltos - Natura non facit saltus & Natureza dá saltos - Facit saltus \\
\hline O mundo tal como é & O mundo tal como se transforma \\
\hline O homem como deve ser & O que é imperativo que ele faça \\
\hline Seus impulsos & Seus motivos \\
\hline O pensamento determina o ser & O ser social determina o pensamento \\
\hline Sentimento & Razão \\
\hline
\end{tabular}

FARBERMAN. Bertolt Brecht y la escena, p. 7-24. In: El teatro de Bertolt Brecht. Un estudio de ocho aspectos. Traducción de León Mirlas. Buenos Aires: Compañia General Fabril Editora, 1963, 380 p. Tradução livre e inédita para o português: Fátima Costa de Lima.

A emergência do Teatro Épico ocorreu simultaneamente ao período de grande declínio, iniciado com o Romantismo, da Poesia Épica como padrão de excelência estética do texto em verso. $\mathrm{E}$, como desafio ainda maior à pretensão vanguardista do teatro, a indústria cultural, criando novos produtos, diminuía atratividade das apresentações teatrais. O declínio da Épica corresponde, como padrão estético da literatura em verso do Ocidente, ao domínio da Lírica.

É sabido que a lírica era, a princípio, apenas um gênero de poesia; porém, com o declínio do grande poema narrativo e do verso dramático, lírica e poesia terminaram por confundir-se. No exame da literatura moderna, um termo pode ser praticamente empregado pelo outro. A principal consequência desta identificação foi que a lírica se tornou depositária por excelência de uma característica essencial da poesia, a de função linguística específica. Considerada como tal, poesia é o tipo de mensagem linguística em que o significante é tão visível quanto o significado, isto é, em que a carne das palavras é tão importante quanto seu sentido. (MERQUIOR, 1997, p.17)

Desse modo, parece que o arsenal da indústria cultural, pela necessidade de apelo cognitivo imediato e fácil às massas, é construído formal e preponderantemente sob o influxo dos gêneros líricos e dramáticos.

Tomando como exemplo o fenômeno da música popular, ao fundir letra e melodia, esse gênero moderno encontrou, nos meios eletrônicos de difusão, amplos espaços para identificação dos indivíduos com o "eu-lírico" dos letristas/compositores, mesmo quando suas obras assumiram posturas críticas e contestadoras à ordem embora estivessem nela e dela fossem fruto -, como é o caso do rock'n roll. Mesmo a 

letiva de um povo: basta lembrarmos do blues e do jazz. A consequência disto é que

Quanto mais os traços líricos se salientarem, tanto menos se constituirá um mundo objetivo, independente das intensas emoções da subjetividade que se exprime. Prevalecerá a fusão da alma que canta com o mundo, não havendo distância entre sujeito e objeto. Ao contrário, o mundo, a natureza, os deuses, são apenas evocados e nomeados para, com maior força, exprimir a tristeza, a solidão ou a alegria da alma que canta. A chuva não será um acontecimento objetivo que umedeça personagens envolvidos em situações e ações, mas uma metáfora para exprimir o estado melancólico da alma que se manifesta; a bem-amada, recordada pelo Eu lírico, não se constituirá em personagem nítida de quem se narrem ações e enredos; será apenas nomeada para que se manifeste a saudade, a alegria ou a dor da voz central. (ROSENFELD, 2011, p.23)

A representação dramática, como apropriada pela mass media, deslocou o público do teatro para a sala de estar das residências: bastava ligar o rádio, de início, para acompanhar as radionovelas; e, alguns anos depois, ligar a televisão para assistir as soap operas. E, no Brasil, as telenovelas, gênero em que a relação dialógica dos personagens das fábulas foi transposta para os aparelhos receptores de sons e de imagens. Não se precisava, doravante, frequentar a sala teatral como o recinto único onde se vê o drama desenrolar-se à frente, com os atores em ação: entre o público e a cena havia, agora, intermediários eletrônicos. ${ }^{2}$

Foi o cinema, também arte dramática e dialógica, que originalmente provocou esse deslocamento. É verdade que, ao contrário do rádio e da televisão, empurra o público para fora de casa; mas se o faz com tanto sucesso há mais de cem anos é porque a projeção da imagem em sala escura materializa a cena e a envolve em efeito mágico inigualável.

O cinema realiza o imaginário em imagens. Imagens fundamentalmente diferentes, por seu estatuto, das que o teatro produzia: porque, no teatro, o que se mostra é a concretude cênica - são homens, madeira, pano, gestos e palavras reais, colocados como "imagens" analogicamente, por metáfora. Dizer sobre o ator que ele é uma imagem só é exato como metáfora. Enquanto que as imagens do cinema são, efetivamente, imagens. Não basta apresentar o análogo de um objeto para que este substituto tenha direito, em sentido próprio, à denominação de imagem. Isto não basta mais: alguma coisa mudou no estatuto da imagem. As imagens do cinematógrafo tornam-se, então, imagens efetivas, imagens de direito, que proporcionam ao imaginário sua ex-sistência apropriada, a exteriorização que lhe convém, relegando todas as outras espécies de imagem à situação de imagens por metáfora. (GUÉNOUN, 2004, p.102)

\footnotetext{
2 Brecht foi um entusiasta do rádio, para o qual chegou a redigir algumas peças. Escreveu, entre 1927 e 1932, cinco textos sobre o novo meio que, reunidos, ficaram conhecidos como "Teoria do Rádio". Acreditava em seu potencial revolucionário porque permitia a interatividade. Quando teve de mudar-se para o exílio, escreveu um pequeno poema sobre sua relação com o rádio: "Você, pequena caixa que trouxe comigo / Cuidando para que suas válvulas não quebrassem / Ao correr do barco ao trem, do trem ao abrigo / Para ouvir o que meus inimigos falassem / Junto ao meu leito, para minha dor atroz / No fim da noite, de manhã bem cedo / Lembrando as suas vitórias e o meu medo: / Prometa jamais perder a voz!". Cf. FREDERICO, Celso. Brecht e a "Teoria do Rádio". Estudos Avançados, vol. 21, número 60, São Paulo, May/Aug, 2007. Disponível em <http://www.scielo.br/scielo.php?script=sci_arttext\&pid=S0103-40142007000200017> Acesso em: 20 de julho 2013.
} 


\title{
CONCLUSÃO
}

A predominância do drama e da lírica na indústria cultural não ergueu barreiras à aproximação com o épico. Bem ao contrário, Walter Benjamin, um dos mais importantes estudiosos do impacto da reprodução técnica nas artes, observou que há uma forma comum entre o teatro épico e os meios de comunicação mais desenvolvidos à época, o rádio e o cinema. No ensaio $O$ que é o teatro épico?, esse pensador alemão, expoente da Teoria Crítica, afirma que, neles, assim como na poesia épica, há autonomia das partes, que podem ser lidas - ou vistas e ouvidas - separadamente, já que têm valor episódico.

\begin{abstract}
As formas de teatro épico correspondem às novas formas técnicas, o cinema e o rádio. Ele está situado no ponto mais alto da técnica. Se o cinema impôs o princípio de que o espectador pode entrar a qualquer momento na sala, de que para isso devem ser evitados os antecedentes muito complicados e de que cada parte, além de seu valor para o todo, precisa ter um valor próprio, episódico, esse princípio tornou-se absolutamente necessário para o rádio, cujo público liga e desliga a cada momento, arbitrariamente, seus alto-falantes. O teatro épico faz o mesmo com o palco. [...] não haverá nada de surpreendente na exigência feita por Brecht a um ator de representar de tal maneira a cena escolhida da perna de pau, pelo mendigo, em Dreigroschenor (Ópera dos três vinténs), que "só por causa desse número as pessoas decidam voltar ao teatro, no momento em que a cena é representada." (BENJAMIN, 1994, p.83)
\end{abstract}

Assim, Walter Benjamim vê que a forma épica, a par de seu conteúdo, aplicase ao conceito de politização da estética, desenvolvido em $A$ obra de arte na era de sua reprodutibilidade técnica, segundo o qual a reprodução, ao permitir a cópia do original, aproxima a arte das massas, tornando mais clara sua nova função social política. Porém isso é uma possibilidade, que depende da intenção do autor; e o teatro, que das artes é a que menos se presta à reprodução, pode politizar a estética apropriando-se de produtos culturais gerados pela reprodução, os quais servem, quase sempre, ao reverso da politização - a estetização da política, de que a supremacia dos gêneros lírico e dramático é tanto causa como consequência. Não foi outra a proposta de Brecht senão transformar a possibilidade em realidade - e, daí, ver a realidade transformada.

\section{BIBLIOGRAFIA}

ARISTÓTELES. Arte poética. Tradução, comentários e índices analítico e onomástico de Eudoro de Souza. São Paulo: Nova Cultural 1991 (Os Pensadores, vol. 2)

BENJAMIN, Walter. A obra de arte na era de sua reprodutibilidade técnica. In: Obras escolhidas I: Magia e técnica, arte e política. Trad. Sérgio Paulo Rouanet. São Paulo: Brasiliense, 1985. 
BERTHOLD, Margot. História mundial do teatro. Tradução de Maria Paula V. Zurawski et alii. São Paulo: Editora Perspectiva, 2011, 502 p.

O que é o teatro épico? Um estudo sobre Brecht. In: Obras escolhidas I: Magia e técnica, arte e política. Trad. Sérgio Paulo Rouanet. São Paulo: Brasiliense, 1985.

FARBERMAN. Bertolt Brecht y la escena, p. 7-24. In: El teatro de Bertolt Brecht. Un estudio de ocho aspectos. Traducción de León Mirlas. Buenos Aires: Compañia General Fabril Editora, 1963. Tradução livre e inédita para o português: Fátima Costa de Lima.

FREDERICO, Celso. Brecht e a "Teoria do Rádio". Estudos Avançados, vol. 21, número 60, São Paulo, May/Aug, 2007. Disponível em <http://www.scielo.br/scielo. php?script=sci_arttext\&pid=S0103-40142007000200017>

GUÉNOUN, Denis. O teatro é necessário? São Paulo: Perspectiva, 2004

MERQUIOR, José Guilherme. A Astúcia da Mímese - Ensaios sobre a Lírica. Rio de Janeiro: Topbboks, 1997

MOISÉS, Massaud. Dicionário de termos literários. São Paulo: Ed.Cultrix, 2004

ROSENFELD, Anatol. O teatro épico. São Paulo: Perspectiva, 2011. 